\title{
Mealybug preference among clover cultivars: testing potential groundcover plants to dissociate mealybugs from grapevines
}

\author{
W. R. Manoharie Sandanayaka ${ }^{1, \star}$, Vicky A. Davis ${ }^{1}$ and Linley K. Jesson ${ }^{2}$ \\ ${ }^{1}$ The New Zealand Institute for Plant \& Food Research Limited (PFR), Mt Albert Research \\ Centre, Private Bag 92169, Mt Albert, Auckland 1142, New Zealand \\ ${ }^{2}$ The New Zealand Institute for Plant \& Food Research Limited, Hawke's Bay Research Centre, \\ Private Bag 1401, Havelock North 4157, New Zealand \\ *Corresponding author: Manoharie.Sandanayaka@plantandfood.co.nz
}

\begin{abstract}
The choice of groundcover plants used under grapevines may reduce the quantity of mealybugs found on grapevines in New Zealand vineyards. Preferences of Pseudococcus calceolariae and P. longispinus mealybugs on five clover cultivars were tested under 'nochoice' and 'choice' conditions. Two plants of each cultivar: 'Karridale'(KS) (Trifolium subterraneum); 'Tripoli' (TW), 'Nomad' (N) (T. repens); 'Crimson cv' (C) (T. incarnatum); and 'Strawberry cv' (S) (T. fragiferum) grown in pots, were arranged in randomised designs for the no-choice and choice tests and inoculated with newly emerged mealybugs. In the no-choice test, significantly more mealybugs (either species) were observed on KS and C than on TW, N, or S plants after 21 days. In the choice test, significantly more $P$. calceolariae were observed on KS than on TW, N, or S, while mealybug numbers on $\mathrm{C}$ were intermediate. Numbers of $P$. longispinus were significantly higher on KS and C than on TW, N or S. Mealybugs demonstrated preferences for KS and C over TW, N or S. These findings could aid development of recommendations for groundcover management in vineyards.
\end{abstract}

Keywords mealybug preference, ground cover, clover, survival, development

\section{INTRODUCTION}

Grapevine leafroll-associated virus 3 (GLRaV-3) is a phloem-restricted virus long thought to be limited to grapes (Vitis spp.) (Petersen \& Charles 1997). This economically important disease adversely influences vine growth, berry yield, fruit colour and flavour. It is transmitted (vectored) by mealybugs, which are commonly found in New Zealand vineyards. The presence of accidentally introduced mealybug species Pseudococcus calceolariae and P. longispinus (Hemiptera: Pseudococcidae) in New Zealand vineyards is described as ubiquitous, such is the frequency with which they are found (Charles et al. 2010). In many vineyards, mealybugs are found on grapevines and/or on the groundcover plant community. There are three or four generations of mealybugs every year with female mealybugs going through three instars and the male mealybugs through two instars before reaching adulthood. Only female mealybugs continue to feed from the first instar to adult, but male mealybugs pupate after the second instar. All life stages are found on the leaves, fruit or under the bark of the host plants. First-instar mealybugs have been identified as the most efficient life stage in transmitting GLRaV-3 (Almeida et al. 2009; Petersen \& Charles 1997).

Only $P$. calceolariae mealybugs were found on roots of grapevines and other host plants in vineyards in Hawke's Bay during 20072008 (Bell et al. 2009). In a subsequent survey 
undertaken in Hawke's Bay vineyards during the 2015-16 growing season, $P$. calceolariae and P. longispinus mealybugs were found on $50-54 \%$ of the groundcover plants (V. Bell, PFR, pers. comm.). Mealybugs were found colonised on many weedy host plant species including clover cultivars. White clover (Trifolium repens L.), in particular, was favoured and was found to sustain mealybugs throughout the growing season (V. Bell pers. comm.). White clover is often sown as part of a groundcover mix because of the benefits of $\mathrm{N}$-fixation, weed suppression, moisture retention, improved soil tilth and crop production of vines (Hartwig \& Ammon 2002; da Veiga et al. 2017). Virus-infected mealybugs on grapevines may rapidly spread the disease to healthy vines. Under these conditions, the likelihood of virus transmission could be reduced, if the vector could remain on ground-cover plants instead of settling and feeding on grapevines.

Other clover species are also commonly grown in vineyards (da Veiga et al. 2017), so the preference of $P$. calceolariae and $P$. longispinus mealybugs for five cultivars from four species of clover was tested to determine if these plants provide an alternative habitat to sustain mealybugs in vineyards and potentially reduce transmission of GLRaV-3 from diseased grape vines to healthy vines. The information could then contribute to the development of grower recommendations for groundcover management.

\section{MATERIALS AND METHODS \\ Insects and plants}

Pseudococcus calceolariae and P. longispinus mealybugs were obtained from laboratory-reared colonies maintained on sprouted potatoes, without exposure to any other host plants. These colonies were reared in isolation at Plant and Food Research, Auckland to avoid cross contamination.

One subterranean clover cultivar, 'Karridale' (KS) (Trifolium subterraneum L.); two white clover cultivars, 'Tripoli' (TW) and 'Nomad' (N) (T. repens); one crimson clover (C) (Trifolium incarnatum L.); and one strawberry clover (S) (Trifolium fragiferum L.) were grown from seeds in a glasshouse in Auckland at $24 \pm 2^{\circ} \mathrm{C}$ and 16L:8D light cycle. Seeds were obtained from Kiwi Seed Company. Two-week-old plants were transplanted into individual pots, two plants of the same clover cultivar per pot. Clover plants were grown in two batches to test plants in the same age group with both mealybug species.

The preference of $P$. calceolariae and $P$. longispinus to the five clover cultivars was assessed by measuring the numbers of live mealybugs and their development under choice and no-choice conditions. Trials with the two mealybug species were held at separate times to prevent crosscontamination. Choice and no-choice tests for the same species were conducted simultaneously in the same glasshouse at $24 \pm 2^{\circ} \mathrm{C}$ and $16: 8 \mathrm{~h}$ light:dark cycle. Trials with $P$. calceolariae were carried out from late January to mid-February 2017 and the trials with $P$. longispinus were carried out from mid-March to early April 2017. The glasshouse space was kept clean, free of mealybugs and plants for a month in between trials to further avoid cross-contamination. Three to four weeks old clover plants were tested with both mealybug species.

\section{No-choice tests}

Five pots of clover plants, a single pot of each cultivar were arranged in a row following a randomised design of eight replicates. An individual pot containing two plants, with a total of 4-6 leaves, was covered with a cylindrical net cage with a wire frame $(22 \mathrm{~cm}$ high $\mathrm{x} 10 \mathrm{~cm}$ diameter). Plants in each pot were inoculated with 30 neonate mealybugs ( $<24$ hours old). The mealybugs were contained in a $0.6-\mathrm{mL}$ Eppendorf tube. The Eppendorf tube was opened and the bottom of the tube inserted into the soil of the pot, next to the plants, to allow the mealybugs to escape from the tube. After a week, the Eppendorf tubes were checked to ensure all the mealybugs escaped from the tubes. The numbers of live mealybugs on each plant and their growth stages were assessed after three weeks for both mealybug species. 


\section{Choice tests}

Five pots (each containing two plants with a total of 4-6 leaves) one from each clover cultivar were arranged to a randomised design in a circle and replicated six times. Each replicate was covered with a cylindrical net cage with a metal frame (40 $\mathrm{cm}$ high $\mathrm{x} 36 \mathrm{~cm}$ diameter). In each replicate, the five clover cultivars were arranged clockwise in the randomised $1-5$ positions in a circle of $32 \mathrm{~cm}$ diameter.

Neonate mealybugs $(n=100)$ were transferred to a 1-mL Eppendorf tube and released by opening the tube at the centre of a soft cardboard platform (24 cm diameter) that was in contact with all five pots in each replicate. The numbers of mealybugs on each plant and their growth stages were assessed after three weeks for both mealybug species. Data were collected for both mealybug species in no-choice and choice tests. Comparisons among clover cultivars in each test were made within mealybug species, either $P$. calceolariae or $P$. longispinus.

\section{Statistical analysis}

A generalised linear model with a quasipoisson link was used to analyse insect count data collected from all four experiments, using $\mathrm{R}$ ( $\mathrm{R}$ Core Team 2017). The quasipoisson family was used because the variance in the data was greater than the mean, violating assumptions for the Poisson distribution. All life stages were combined because there were very few counts at the second and third instar category. Model assumptions were checked visually with diagnostic plots. The effects of replicate and position (in case there were any strong spatial and temporal effects) were included. For all experiments, the statistical model contained the fixed effects of replicate, position and clover cultivar. Initially, the interaction between clover species and position was tested as was the interaction between clover species and replicate. Neither of these was significant so they were removed from the final model.

\section{RESULTS}

The majority of the neonate mealybugs escaped from the Eppendorf tubes. After a week, examination found only one-two dead mealybugs across a few tubes, with no difference between mealybug species. The growth of the clover plants varied among cultivars with KS and $\mathrm{C}$ growing more vigorously compared with TW, S and N. After three weeks, mealybugs were found on the base of the stem and on the leaves of the clover plants regardless of species. The mean total numbers of mealybugs on each plant varied among cultivars and ranged from 0 to 24 individuals per plant. Mealybug development was not different among clover cultivars, with both mealybug species having generally developed through to third instar, while cocooned males were found on the majority of the plants in all four experiments and they were included for data analysis. A few plants in each experiment had a mixture of second and third instars.

\section{No-choice test with Pseudococcus calceolariae}

The mean number of mealybugs on TW, N and $S$ was $4.0 \pm 2.3,3.9 \pm 2.2,4.5 \pm 2.0$ respectively, significantly lower than that for $\mathrm{C}(11.3 \pm 3.4)$ and KS (11.3 \pm 1.3$)$ (Tukey's post hoc test, $\mathrm{P}<0.001$ for all comparisons) (Fig. 1a). There was no effect of replicate or plant position on mealybug numbers (Fig. 2a).

\section{Choice test with Pseudococcus calceolariae}

Plants of KS had significantly higher numbers $(12.0 \pm 6.0)$ of $P$. calceolariae than those of $\mathrm{N}(2.5$ $\pm 2.3)$, TW $(2.5 \pm 2.0)$ or S $(2.5 \pm 2.3)$ (Tukey's post hoc test $\mathrm{P}<0.001$ for all comparisons) (Fig. $1 b)$, while $C(5.3 \pm 2.0)$ had numbers of $P$. calceolariae intermediate to those on the two groups of (N, TW and S), and KS. There was no effect of replicate or plant position on mealybug numbers (Fig. 2b).

\section{No-choice test with Pseudococcus longispinus}

There was a significant effect of clover cultivar on the number of $P$. longispinus in the no choice experiment $(\mathrm{P}<0.001)$. A grouping of TW $(1.9$ $\pm 1.2), \mathrm{N}(3.8 \pm 2.8)$ and $\mathrm{S}(4.9 \pm 3.1)$ had very 

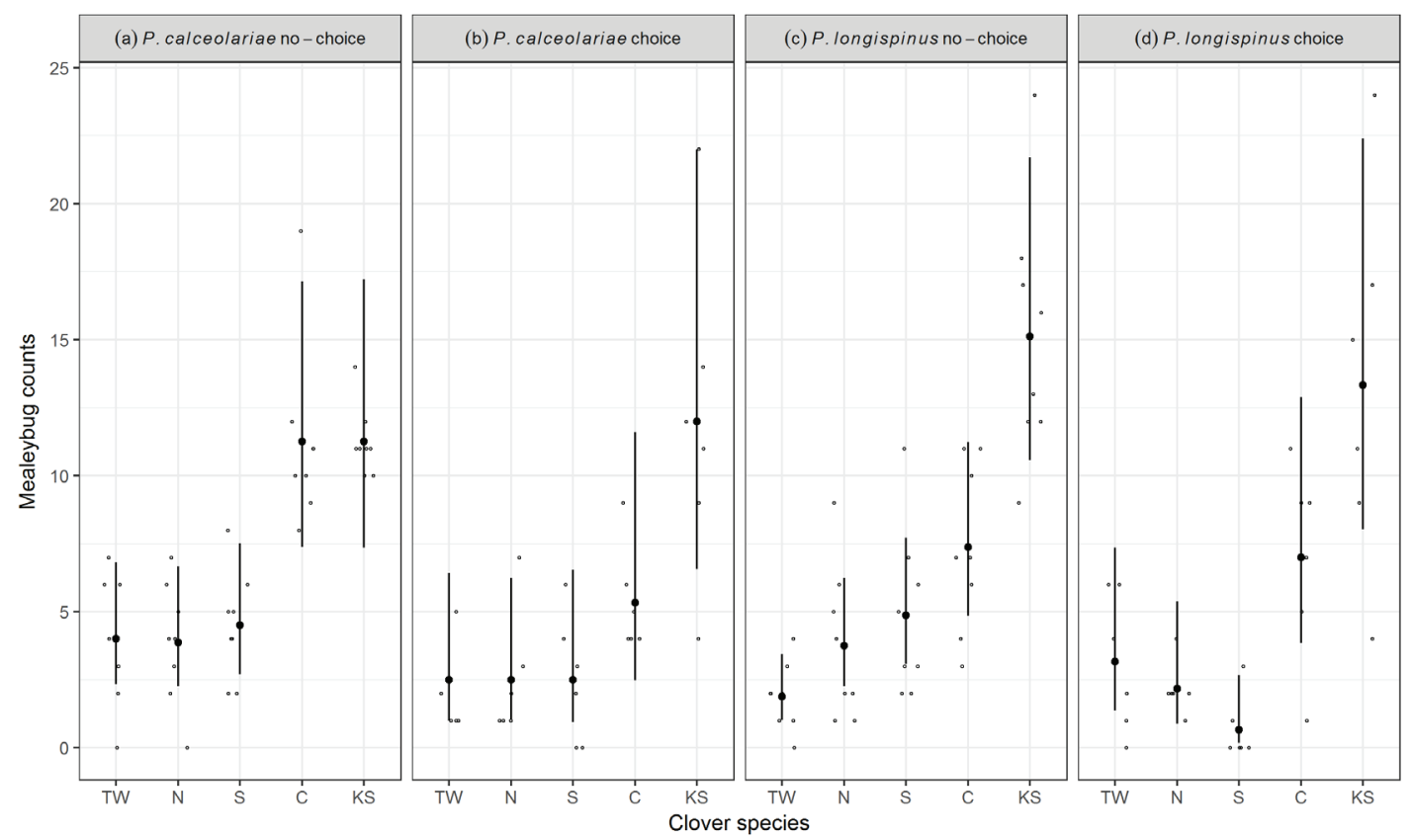

Figure 1 Predicted mean and 95\% confidence intervals for Pseudococcus calceolariae and Pseudococcus longispinus counts on five clover cultivars ('Tripoli' (TW), 'Nomad' (N), 'Strawberry cv' (S), 'Crimson $\mathrm{cv}^{\prime}(\mathrm{C})$ and, 'Karridale' (KS)) in the no-choice and choice tests, averaged over replicates. Points on lines are the predicted means, small points are the raw data. Lines not overlapping can be considered significantly different.

low numbers of $P$. longispinus, with KS (15.1 $\pm 4.7)$ having significantly higher numbers of mealybugs than $C(7.4 \pm 3.1)$. Numbers of mealy bugs on $\mathrm{C}$ were intermediate between $\mathrm{KS}$ and on the grouping of TW, N, and S, with counts on C significantly higher than the TW, N, and S group (Fig. 1c).

There was a significant effect of replicate $(\mathrm{P}<0.001)$, but the interaction between replicate and clover cultivar was not significant $(\mathrm{P}>0.05)$, suggesting that the responses of $P$. longispinus to clover were the same across all replicates. There was also a significant effect of position on the numbers of mealybugs $(\mathrm{P}=0.003)$. For $P$. longispinus, plants at position 3 always had higher numbers of mealybugs than at the other positions (Fig. 2c). However, there was no interaction between cultivar and position, suggesting that any effects of position did not change regardless of which cultivar was at a particular position.

\section{Choice test with Pseudococcus longispinus}

While there was a significant effect of replicate $(\mathrm{P}=0.012)$, there was no interaction between replicates and clover cultivars, suggesting that the responses of $P$. longispinus to clover was the same across all replicates.

Mean numbers of $P$. longispinus differed between the different cultivars of clover $(\mathrm{P}<0.001)$. There were essentially two groupings of cultivars: TW, $\mathrm{N}$ and $\mathrm{S}$ had very low numbers of $P$. longispinus $(<3.2 \pm 2.6)$, while $C(7 \pm 3.6)$ and KS (13.3 \pm 6.9$)$ had significantly higher mean numbers of $P$. longispinus, with significant differences between these two groups (Tukey's post hoc test, $\mathrm{P}<0.001$ ) (Fig. 1d).

There was a significant effect of position on the numbers of mealybugs, with plants at position 3 having higher numbers of $P$. longispinus than those at other positions (Fig. 2d). However, the interaction of species of clover and position was 


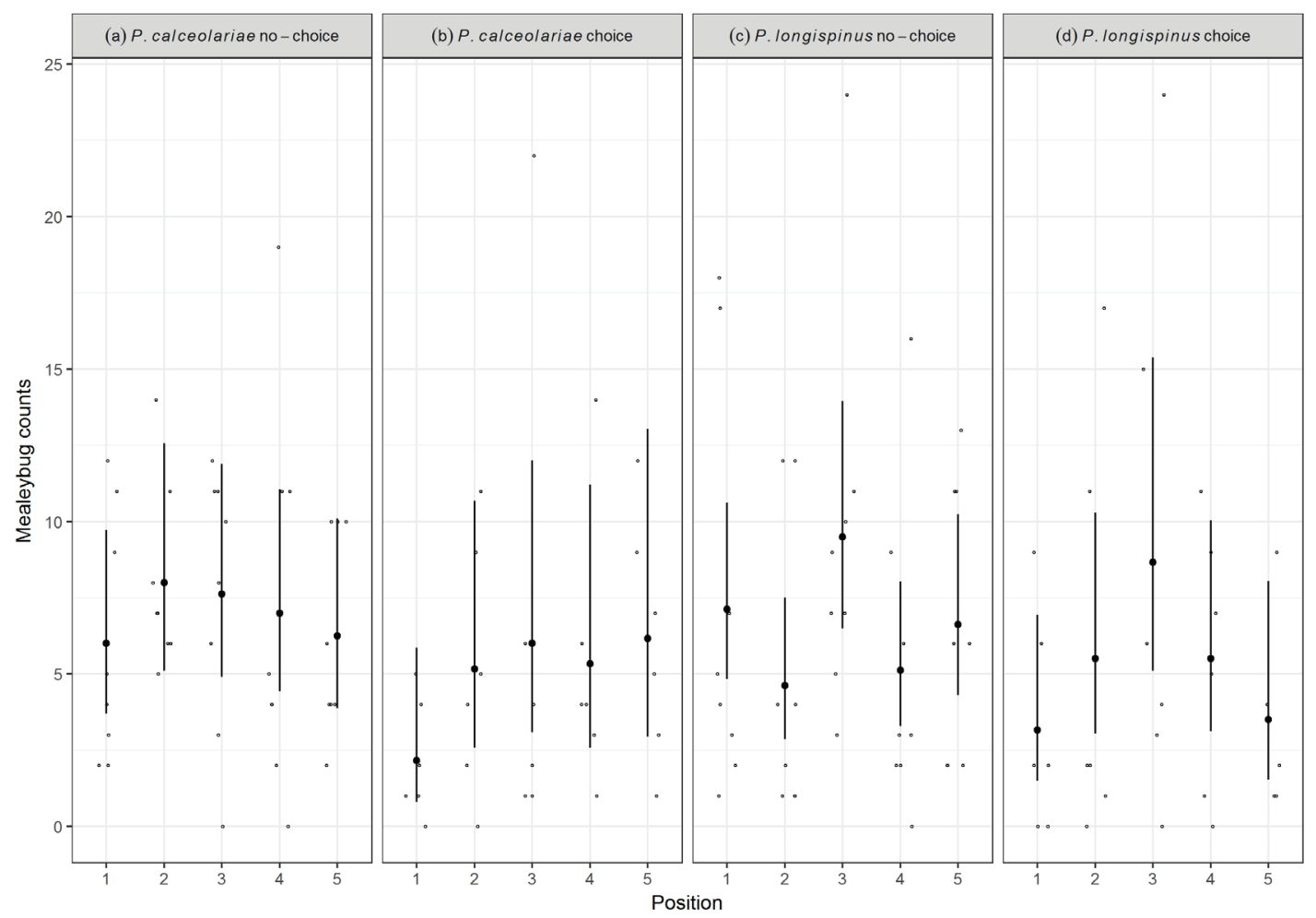

Figure 2 Predicted mean and 95\% confidence intervals for Pseudococcus calceolariae and Pseudococcus longispinus counts across five plant positions in no-choice and choice tests. Points on lines are the predicted means, small points are the raw data. Lines not overlapping can be considered significantly different.

not significant, suggesting that any effects of position did not change when the clover cultivars were at the different positions.

\section{DISCUSSION}

The objective of this study was to assess the suitability of different clover cultivars commonly used in vineyard groundcover as hosts of the two major pest mealybugs, $P$. calceolariae and $P$. longispinus. Results from the no-choice test showed that higher survival of $P$. calceolariae and $P$. longispinus occurred on subterranean clover (KS) and crimson clover cultivar (C), than on either the two white clover cultivars (TW and N) or strawberry clover cultivar (S). Regardless of the cultivar, the highest numbers of mealybugs were found on KS under choice conditions, indicating the strongest preference and survival. After KS, more mealybugs were found on $\mathrm{C}$ than on TW, $\mathrm{N}$ or $\mathrm{S}$. The more vigorous plant growth that was observed with KS and C compared with TW, S or $\mathrm{N}$ may have influenced the attractiveness to first instar mealybugs and enhanced mealybug survival on those clover cultivars.

There was no difference in mealybug development among clover cultivars, indicating that mealybugs were able to feed successfully on all the plants on which they were settled. Individuals of both mealybug species developed up to third instar when the clover plants were assessed after three weeks.

Studies on the vine mealybug Planococcus ficus (Signoret) report that GLRaV-3 does not replicate within the mealybug itself and is semi- 
persistent (Tsai et al. 2008), which means the virus is lost over time after a mealybug ceases feeding on an infected vine. Moreover, in respect of $\mathrm{Pl}$. ficus, the virus is lost during the moulting process, and it is not transmitted from female to offspring (Tsai et al. 2008). Currently, no research has been undertaken to determine if the virus is lost from $P$. calceolariae and $P$. longispinus when feeding on clover plants. Evaluating GLRaV-3 acquisition, retention, and loss mechanism in mealybugs, and the timeframes involved, is an important element to understanding and refining any clover management strategy. Previously it was assumed that if mealybugs are not on grapevines, they can neither acquire the virus nor transmit it. However, a recent study shows GLRaV-3 infecting a non-Vitis plant, Nicotiana benthamiana Domin (Solanales: Solanaceae) (Prator et al. 2017). Therefore, further testing is required to confirm whether or not GLRaV-3 can be retained on, or acquired from clover lines.

There is no obvious explanation for the higher numbers of $P$. longispinus found on the plants at position number 3 of the replicates in both choice and no-choice tests, which was different from the findings for $P$. calceolariae. Pots were arranged in rows in no-choice tests, and in circles in choice tests. This difference in layout does not explain the position 3 effects seen.

From the results of this study, we suggest that in vineyards mealybugs could survive more on subterranean clover and crimson clover than the either white clover or strawberry clover. If this were proved to be the case in the field, we hypothesise that the adverse effects of GLRaV-3 could be reduced by growing $\mathrm{KC}$ and $\mathrm{C}$ as groundcover. This alternative habitat may sustain mealybugs and if the plants attracted mealybugs away from grapevines, it could potentially reduce transmission rates of GLRaV-3 from diseased to healthy grape vines. Additionally, the nectar produced by flowering clover plants in the groundcover, may attract mealybug parasitoids (e.g. Anagyrus fusciventris, Tetracnemoidea brevicornis (Hymenoptera: Encyrtidae)), thereby potentially increasing parasitism rates amongst the mealybug population. Hence groundcover management could increase vine yield by reducing grapevine susceptibility to mealybugs. Research is needed to support this hypothesis.

\section{ACKNOWLEDGEMENTS}

We thank PFR colleagues Vaughn Bell for his support and guidance for this study, Natalie Page and David Logan for their valuable comments on the earlier version of this paper, and Asha Chhagan for providing mealybugs. We also thank the anonymous referee for suggestions to improve an earlier draft of this manuscript. This work is part of the Wine Research programme of The New Zealand Institute for Plant \& Food Research Limited (PFR), which is funded by the MBIE Strategic Science Investment Fund, delivered by PFR in consultation with $\mathrm{New}$ Zealand Winegrowers Inc.

\section{REFERENCES}

Almeida RPP, Tsai C, Daane KM 2009. The role of seasonality on mealybug transmission of grapevine leafroll-associated viruses: an ecological hypothesis. In: 16th Meeting of the International Council for the Study of Virus and Virus-like Diseases of the Grapevine, p. 278.

Bell VA, Bonfiglioli RGE, Walker JTS, Lo PL, Mackay JF, McGregor SE 2009. Grapevine leafroll-associated Virus 3 persistence in Vitis vinifera remnant roots. Journal of Plant Pathology 91: 527-533.

Charles JG, Bell VA, Lo PL, Cole LM, Chhagan A 2010. Mealybugs (Hemiptera: Pseudococcidae) and their natural enemies in New Zealand vineyards from 1993-2009. New Zealand Entomologist 33: 84-91.

da Veiga M, Feldberg NP, Nava G, Bettoni JC 2017. Winter cover crops affecting physical and chemical soil attributes in a commercial vineyard. Ciencia Rural 47: e20160827. DOI: 10.1590/0103-8478cr20160827.

Hartwig NL, Ammon HU 2002. 50th Anniversary - Invited article - Cover crops and living mulches. Weed Science 50: 688-699.

Petersen CL, Charles JG 1997. Transmission of grapevine leafroll associated closteroviruses 
by Pseudococcus longispinus and $P$. calceolariae. Plant Pathology 46: 509-515.

Prator CA, Kashiwagi CM, Vončina D, Almeida RPP 2017. Infection and colonization of Nicotiana benthamiana by Grapevine leafrollassociated virus 3. Virology 510: 60-66.

RCore Team 2017. R: A language and environment for statistical computing. R Foundation for Statistical Computing, Vienna, Austria. URL https://www.R-project.org/.

Tsai CW, Chau J, Fernandez L, Bosco D, Daane KM, Almeida RPP 2008. Transmission of Grapevine leafroll-associated virus 3 by the vine mealybug (Planococcus ficus). Phytopathology 98: 1093-1098. 